\title{
Resistive index and peak systolic velocity for congenital talipes equinovarus: A color Doppler ultrasonography study
}

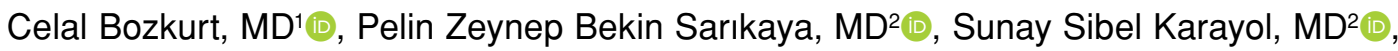

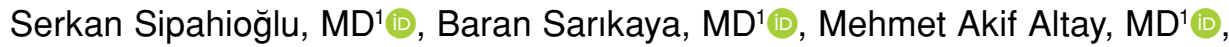 \\ Abdurrahim Dusak, MD²(1), Mehmet Demir, MD'1(D) \\ ${ }^{1}$ Department of Orthopedics and Traumatology, Harran University Faculty of Medicine, Şanlıurfa, Turkey \\ ${ }^{2}$ Department of Radiology, Harran University Faculty of Medicine, Şanlıurfa, Turkey
}

Congenital talipes equinovarus (clubfoot) is a disease that is treated frequently in orthopedics clinics. Its incidence is $1-2$ per 1,000 live births. ${ }^{[1]}$ Cavus, adductus, varus, and equinus deformities are observed in clubfoot patients; ${ }^{[2]}$ each of these contributes to various bone, muscle, vascular, and neurological problems. ${ }^{[3]}$ Vascular deficiencies have been suggested as one of the underlying etiologies of clubfoot.

Various studies using arteriography, ${ }^{[3]}$ continuous wave Doppler ultrasonography (DU) ${ }^{\left[{ }^{[4]}\right.}$ color Doppler ultrasonography (CDU), ${ }^{[2,4-6]}$ and magnetic resonance image angiography ${ }^{[3,7]}$ were performed to show arterial patterns in clubfoot patients. Deficiency of the anterior tibial artery and dorsalis pedis $(\mathrm{dp})$ artery were demonstrated in $6.7-86 \%$ of patients. ${ }^{[4]}$

Many researchers have reported that CDU is a reliable technique and can be used as a suitable alternative for arteriography. ${ }^{[1,8]}$ Several CDU studies have been undertaken to investigate the arterial structures in clubfoot patients. In these studies,

Received: November 08, 2019

Accepted: January 01, 2020

Published online: March 26, 2020

Correspondence: Celal Bozkurt, MD. Harran Üniversitesi Tıp

Fakültesi Ortopedi ve Travmatoloji Anabilim Dalı, 63300

Şanlıurfa, Türkiye.

E-mail: bozkurt.celal@gmail.com

Doi: 10.5606/ehc. 2020.72283

Presented in the Turkish Bone and Joint Society Congress, April 27 - May 01 2019, Muğla, Turkey.

Citation: Bozkurt C, Bekin Sarıaya PZ, Karayol SS, Sipahioğlu S, Sarıkaya B, Altay MA, et al. Resistive index and peak systolic velocity for congenital talipes equinovarus: A color Doppler ultrasonography study. Jt Dis Relat Surg 2020;31(2):169-174.

\section{ABSTRACT}

Objectives: This study aims to investigate whether resistive index (RI) and peak systolic velocity (PSV) are suitable parameters to determine if a clubfoot differs from feet of the normal population.

Patients and methods: Fifty-four feet of 27 clubfoot patients (22 males, 5 females; mean age $30.4 \pm 16.3$ months; range, 5 to 72 months) were included in this retrospective study conducted between December 2017 and January 2019. Twentyseven feet were conservatively treated, 19 had surgical treatment, and eight feet were healthy in patients with unilateral clubfoot. In addition, 22 feet of 11 normal controls ( 6 males, 5 females; mean age $33.4 \pm 15.3$ months; range, 15 to 60 months) were studied. Color Doppler ultrasonography examinations were performed to evaluate the three major arteries of the leg and foot: dorsalis pedis (dp), tibialis posterior (tp), and popliteal (pop). Color filling, flow direction, spectral analysis, velocity, and RI were examined.

Results: With the exception of the dp artery RI, the PSV and RI values for all arteries differed significantly from those of the control group. There were no significant differences among the conservative, surgical, and healthy groups, while there were significant differences between each of the treated groups and the control group. Tibialis posterior artery PSV and pop artery RI were the best parameters to identify clubfoot and the cut-off points were $54 \mathrm{~cm} / \mathrm{second}$ and 0.77 , respectively.

Conclusion: Peak systolic velocity and RI may be accepted as important parameters for identification of clubfoot deformity. Tibialis posteriorartery PSV and pop artery RI are the bestdetailed parameters for this examination.

Keywords: Clubfoot, color Doppler ultrasonography, microcirculation, resistive index.

analysis parameters included arterial diameter, direction of arterial flow, arterial flow pattern and velocity, and lumen filling. ${ }^{[1,2,4-6,9]}$

The resistive index (RI) or Pourcelot index is an important parameter used to characterize arterial wave forms in DU (Figure 1). ${ }^{[10]}$ The RI is the peak systolic velocity (PSV) and end-diastolic velocity 
(EDV) difference divided by the PSV (PSV-EDV/PSV); its value ranges from 0 to 1 , and it demonstrates the decrement of arterial blood flow at the end of the diastolic period. ${ }^{[1]]}$ Thus, RI is a good parameter to assess microcirculation in pathological and physiological conditions. ${ }^{[12]}$

Because of the possibility of vascular pathology in clubfoot patients, we investigated microcirculation in these patients. To the best of our knowledge, there have been no publications regarding RI and PSV in clubfoot patients. We hypothesized that vascular deficiency is a component of clubfoot and RI and PSV are significant parameters in clubfoot patients, with values that differ from those in the normal population, and that RI and PSV may change in accordance with the severity of clubfoot and may thus be used as prognostic criteria. ${ }^{[13]}$ Therefore, in this study, we aimed to investigate whether RI and PSV are suitable parameters to determine if a clubfoot differs from feet of the normal population.

\section{PATIENTS AND METHODS}

This retrospective study of 27 patients (22 males, 5 females; mean age $30.4 \pm 16.3$ months; range, 5 to 72 months) with idiopathic clubfoot deformity was conducted at Harran University Faculty of Medicine between December 2017 and January 2019. All data of the patients were collected prospectively and reviewed retrospectively. The deformity was unilateral in eight patients (four right

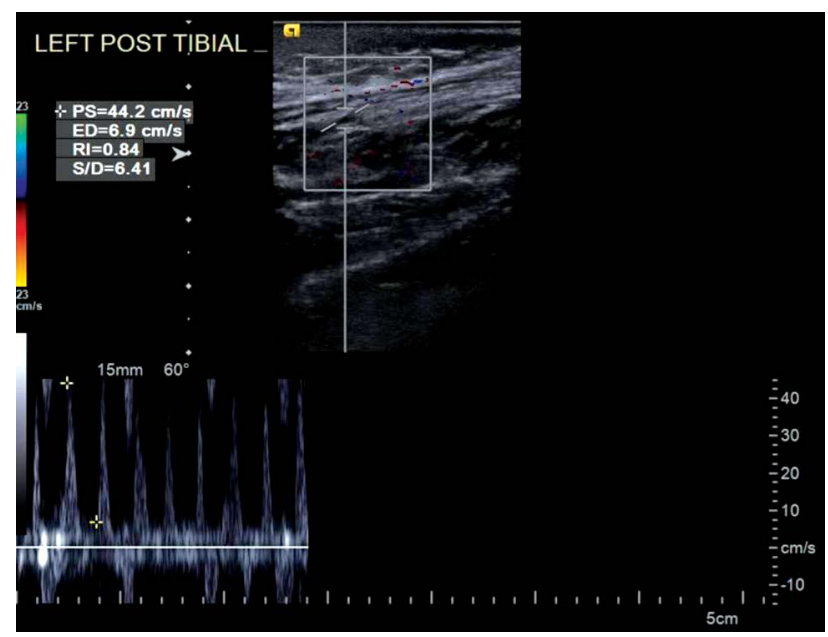

FIGURE 1. A 32-month-old child's left tibialis posterior artery color Doppler ultrasonography examination. Child was in conservative group. Peak systolic velocity (PSV): $44.2 \mathrm{~cm} /$ second and resistive index (RI): 0.84 . Tibialis posterior artery PSV $\leq 54 \mathrm{~cm} /$ second, $\mathrm{RI}>0.77$.

PS: Peak systolic velocity; ED: En diastolic velocity; S/D: Systolic velocity/ diastolic velocity. sides and four left sides) and bilateral in 19 patients. Twenty-seven feet were treated conservatively, whereas 19 feet were treated surgically (extensive posteromedial surgical release) and eight feet were healthy. In addition, 11 normal babies (6 males, 5 females; mean age $33.4 \pm 15.3$ months; range, 15 to 60 months) (22 feet) with no family history of clubfoot and no other disease were selected as the control group. The study protocol was approved by the Harran University Faculty of Medicine Ethics Committee (13/07/2018-28357). A written informed consent was obtained from parents of each participant. The study was conducted in accordance with the principles of the Declaration of Helsinki.

There were four groups in the study. The conservative group consisted of feet that were treated with the Ponseti method (manipulation, casting, and percutaneous Achilles tenotomy); the mean patient age was $30.96 \pm 18.68$ months. The surgical group consisted of feet that were indicated for extensive posteromedial surgical release; the mean patient age was $32.5 \pm 14.2$ months. The healthy group consisted of the contralateral normal feet of patients who had unilateral clubfoot deformity; the mean patient age was $23.8 \pm 11.3$ months. The control group consisted of the feet of children without disease, as described above; the mean control subject age was $33.5 \pm 15.3$ months.

All patients and controls were examined by the same experienced radiologist using a Philips X Matrix EPIQ7 ultrasound instrument (Philips MedicalSystems

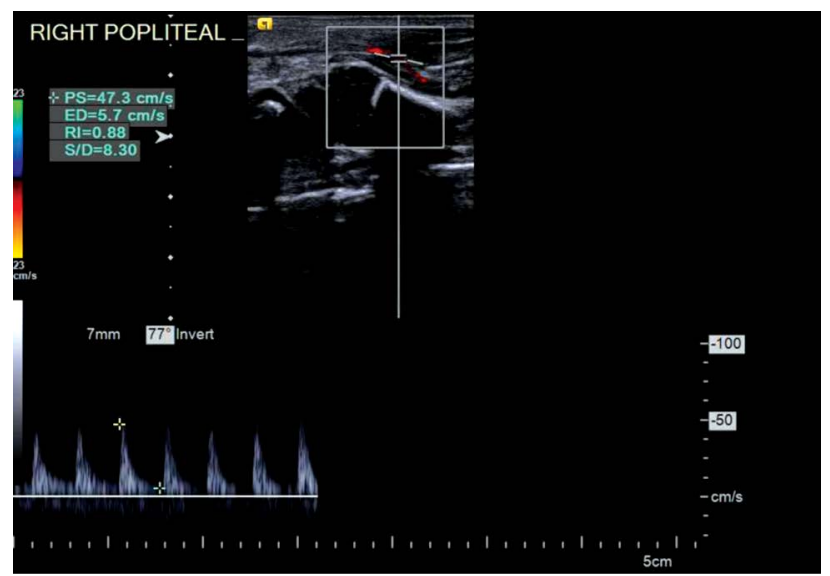

FIGURE 2. A 36-month-old child's right popliteal artery color Doppler ultrasonography examination. Child was in surgical group. Peak systolic velocity (PSV): $47.3 \mathrm{~cm} /$ second and resistive index (RI): 0.88 . Popliteal artery PSV $\leq 57.5 \mathrm{~cm} /$ second, $\mathrm{RI}>0.77$.

PS: Peak systolic velocity; ED: En diastolic velocity; S/D: Systolic velocity/ diastolic velocity. 
Corporation, Best, Netherlands). A 12-3 Hz linear array transducer was used during the examinations. All babies were sleeping or calm after feeding during the examination. In the surgical group, DU examinations were performed before surgery. Bilateral CDU was performed to evaluate the three major arteries of the leg and foot: $\mathrm{dp}$, tibialis posterior (tp), and popliteal (pop). The transducer was placed over the dorsum of the foot on the intermetatarsal region of the first and second metatarsal bones, posterior to the medial malleolus and pop fossa, respectively. Color filling, flow direction, spectral analysis, velocity, and RI were examined (Figures 1, 2).

\section{Statistical analysis}

The distributions of continuous variables were tested for normality using the Shapiro-Wilk test. The Kruskal-Wallis and Dunn's multiple comparison tests were used to compare categorical data among groups. Receiver operating characteristic (ROC) curve analysis was performed to determine the optimal cutoff values for numerical variables. Mean \pm standard deviations were determined as descriptive statistics. Statistical analysis was performed with the IBM SPSS for Windows version 24.0 software (IBM Corp.,
Armonk, NY, USA), and $p$ values $<0.05$ were considered statistically significant.

\section{RESULTS}

There were no statistically significant differences in mean age among the groups. The pop, tp, and $\mathrm{dp}$ arteries were present in all feet. The PSV and RI values differed significantly among the four groups, with the exception of the $\mathrm{dp}$ artery RI (RIdp) (Table I).

Subgroup comparisons were performed separately for all significant variables. These comparisons showed that there were no significant differences among the conservative, surgical, and healthy groups with respect to the PSV. Comparisons of the PSV values for the conservative versus control groups, and for the surgical versus control groups showed significant differences for all arteries. Comparisons of PSV values for the healthy versus control groups showed significant differences for the tp artery alone (Table II). Comparisons of the RI values for the tp and pop arteries showed no significant differences among the conservative, surgical, and healthy groups.

\section{TABLE I}

Comparison of peak systolic velocity and resistive index values of dorsalis pedis, tibialis posterior, and popliteal arteries for all groups

\begin{tabular}{|c|c|c|c|c|c|}
\hline & Conservative $(n=27)$ & Surgical $(n=19)$ & Healthy $(n=8)$ & Control $(n=22)$ & \\
\hline Variable & Mean $\pm S D$ & Mean $\pm S D$ & Mean士SD & Mean $\pm S D$ & $p$ \\
\hline PSVdp & $30.24 \pm 17.78$ & $30.97 \pm 15.59$ & $40.93 \pm 10.16$ & $59.91 \pm 17.87$ & $0.001^{*}$ \\
\hline RIdp & $0.79 \pm 0.11$ & $0.77 \pm 0.11$ & $0.84 \pm 0.05$ & $0.74 \pm 0.11$ & 0.092 \\
\hline PSVtp & $42.71 \pm 30.35$ & $31.51 \pm 12.52$ & $48.53 \pm 24.04$ & $73.82 \pm 14.64$ & $0.001^{*}$ \\
\hline RItp & $0.86 \pm 0.07$ & $0.84 \pm 0.06$ & $0.86 \pm 0.05$ & $0.71 \pm 0.1$ & $0.001^{*}$ \\
\hline PSVpop & $55.65 \pm 22.74$ & $50.79 \pm 25.34$ & $58.98 \pm 19.37$ & $76.05 \pm 20.82$ & $0.002^{*}$ \\
\hline RIpop & $0.89 \pm 0.05$ & $0.84 \pm 0.09$ & $0.88 \pm 0.07$ & $0.71 \pm 0.07$ & $0.001^{*}$ \\
\hline
\end{tabular}

SD: Standard deviation; PSVdp: Dorsalis pedis artery peak systolic velocity; RIdp: Dorsalis pedis artery resistive index; PSVtp: Tibialis posterior artery peak systolic velocity; RItp: Tibialis posterior artery resistive index; PSVpop: Popliteal artery peak systolic velocity; RIpop: Popliteal artery resistive index; There are statistically significant differences for all variables except dorsalis pedis artery resistive index; ${ }^{\star}$ Significant at 0.05 level; Kruskal-Wallis test.

\begin{tabular}{|c|c|c|c|c|c|c|c|}
\hline \multicolumn{8}{|c|}{$\begin{array}{c}\text { TABLE II } \\
\text { tly different grou }\end{array}$} \\
\hline & Group & $\begin{array}{c}\text { Conservative- } \\
\text { surgical }\end{array}$ & $\begin{array}{c}\text { Conservative- } \\
\text { healthy }\end{array}$ & $\begin{array}{c}\text { Conservative- } \\
\text { control }\end{array}$ & $\begin{array}{l}\text { Surgical- } \\
\text { healthy }\end{array}$ & $\begin{array}{c}\text { Surgical- } \\
\text { control }\end{array}$ & $\begin{array}{c}\text { Healthy- } \\
\text { control }\end{array}$ \\
\hline \multirow{3}{*}{ के } & Dorsalis pedis artery & 0.734 & 0.099 & $0.001^{*}$ & 0.182 & $0.001^{*}$ & 0.061 \\
\hline & Tibialis posterior artery & 0.199 & 0.321 & $0.001^{*}$ & 0.063 & $0.001^{*}$ & $0.020^{*}$ \\
\hline & Popliteal artery artery & 0.693 & 0.626 & $0.001^{*}$ & 0.456 & $0.001^{*}$ & 0.067 \\
\hline \multirow{2}{*}{$\bar{\simeq}$} & Tibialis posterior artery & 0.283 & 0.777 & $0.001^{*}$ & 0.623 & $0.001^{*}$ & $0.001^{*}$ \\
\hline & Popliteal artery & 0.107 & 0.907 & $0.001^{*}$ & 0.302 & $0.001^{*}$ & $0.001^{*}$ \\
\hline
\end{tabular}


Comparisons of the RI values for conservative versus control, surgical versus control, and healthy versus control groups showed significant differences for all arteries (Table II).

The ROC curve analysis was performed to determine the optimal cut-off values for PSV and RI values to differentiate clubfoot groups from the control group. The area under the ROC curve (AUC) was calculated for all arteries for each group. First, each group was compared with the control group; then, all groups (conservative, surgical, and healthy) together were compared with the control group. The AUC values for PSVpop for each analysis were $<0.8$, whereas they were $>0.8$ for each analysis for PSVdp and PSVtp. Notably, the AUC values for PSVtp were higher than those for other arteries. The PSVtp AUC values were $0.892 \pm 0.05(\mathrm{p}=0.001)$, $0.993 \pm 0.001(\mathrm{p}=0.001)$, and $0.824 \pm 0.13(\mathrm{p}=0.001)$ for the conservative versus control, surgical versus control, and healthy versus control comparisons, respectively (Table III). Furthermore, cut-off points for the PSV were determined for all groups together, relative to the control group. The AUC values were $0.879 \pm 0.04$ $(\mathrm{p}=0.001), 0.918 \pm 0.03(\mathrm{p}=0.001)$, and $0.780 \pm 0.06(\mathrm{p}=0.001)$ for PSVdp, PSVtp, and PSVpop, respectively. The AUC value for PSVtp was significantly higher than that

\begin{tabular}{|c|c|c|c|}
\hline \multicolumn{4}{|c|}{$\begin{array}{c}\text { TABLE III } \\
\text { Area under curve and cut-off analyses for PSV values }\end{array}$} \\
\hline \multirow[t]{2}{*}{ Group } & $\mathrm{AUC} \pm \mathrm{SE}$ & & \\
\hline & Mean \pm SD & $p$ & Cut-off \\
\hline \multicolumn{4}{|c|}{ Conservative vs. control } \\
\hline PSVdp & $0.891 \pm 0.047$ & 0.001 & $\leq 42$ \\
\hline PSVtp & $0.892 \pm 0.05$ & 0.001 & $\leq 52.6$ \\
\hline PSVpop & $0.785 \pm 0.067$ & 0.001 & $\leq 57.2$ \\
\hline \multicolumn{4}{|c|}{ Surgical vs. control } \\
\hline PSVdp & $0.892 \pm 0.049$ & 0.001 & $\leq 42$ \\
\hline PSVtp & $0.993 \pm 0.001$ & 0.001 & $\leq 54$ \\
\hline PSVpop & $0.794 \pm 0.07$ & 0.001 & $\leq 61.7$ \\
\hline \multicolumn{4}{|c|}{ Healthy vs. control } \\
\hline PSVdp & $0.807 \pm 0.08$ & 0.001 & $\leq 54$ \\
\hline PSVtp & $0.824 \pm 0.13$ & 0.001 & $\leq 44.5$ \\
\hline PSVpop & $0.730 \pm 0.11$ & 0.035 & $\leq 54$ \\
\hline \multicolumn{4}{|c|}{ All groups vs. control } \\
\hline PSVdp & $0.879 \pm 0.04$ & 0.001 & $\leq 42$ \\
\hline PSVtp & $0.918 \pm 0.03$ & 0.001 & $\leq 54$ \\
\hline PSVpop & $0.780 \pm 0.06$ & 0.001 & $\leq 57.5$ \\
\hline
\end{tabular}

for other arteries. The cut-off point for PSVtp was determined to be $\leq 54 \mathrm{~cm} /$ second (Table III).

The AUC values for RItp and RIpop were $>0.8$ for each analysis. In particular, the AUC values for RIpop were higher than those for other arteries. The RIpop AUC values were $0.980 \pm 0.015(\mathrm{p}=0.001)$, $0.868 \pm 0.06(\mathrm{p}=0.001)$, and $0.963 \pm 0.03(\mathrm{p}=0.035)$ for the conservative versus control, surgical versus control, and healthy versus control comparisons, respectively (Table IV). Finally, cut-off points were determined for the RI for all groups together, relative to the control group. The AUC values were $0.646 \pm 0.08(\mathrm{p}=0.057)$, $0.885 \pm 0.06(\mathrm{p}=0.001)$, and $0.938 \pm 0.06(\mathrm{p}=0.001)$ for RIdp, RItp, and RIpop, respectively. The AUC value for RIpop was significantly higher than that for other arteries. The cut-off points for all groups relative to the control group were 0.77 for each group (Table IV).

\section{DISCUSSION}

Before beginning the treatment of clubfoot deformity, prognosis prediction is important to achieve an optimal treatment strategy. Existing classification systems cannot appropriately guide treatment. ${ }^{[3]}$ Vascular deficiency has been suggested to contribute to clubfoot deformity. Magnetic resonance angiography

\begin{tabular}{|c|c|c|c|}
\hline \multicolumn{4}{|c|}{$\begin{array}{l}\text { TABLE IV } \\
\text { id cut-off analys }\end{array}$} \\
\hline \multirow[t]{2}{*}{ Group } & $\mathrm{AUC} \pm \mathrm{SE}$ & & \\
\hline & Mean $\pm S D$ & $p$ & Cut-off \\
\hline \multicolumn{4}{|c|}{ Conservative vs. control } \\
\hline RIdp & $0.625 \pm 0.085$ & 0.141 & $>0.79$ \\
\hline RItp & $0.886 \pm 0.058$ & 0.001 & $>0.77$ \\
\hline RIpop & $0.980 \pm 0.015$ & 0.001 & $>0.77$ \\
\hline \multicolumn{4}{|c|}{ Surgical vs. control } \\
\hline Rldp & $0.612 \pm 0.09$ & 0.217 & $>0.77$ \\
\hline RItp & $0.872 \pm 0.06$ & 0.001 & $>0.77$ \\
\hline Rlpop & $0.868 \pm 0.06$ & 0.001 & $>0.75$ \\
\hline \multicolumn{4}{|c|}{ Healthy vs. control } \\
\hline Rldp & $0.793 \pm 0.08$ & 0.001 & $>0.78$ \\
\hline RItp & $0.824 \pm 0.13$ & 0.001 & $>0.77$ \\
\hline Rlpop & $0.963 \pm 0.03$ & 0.035 & $>0.77$ \\
\hline \multicolumn{4}{|c|}{ All groups vs. control } \\
\hline Rldp & $0.646 \pm 0.08$ & 0.057 & $>0.77$ \\
\hline RItp & $0.885 \pm 0.06$ & 0.001 & $>0.77$ \\
\hline Rlpop & $0.938 \pm 0.06$ & 0.001 & $>0.77$ \\
\hline
\end{tabular}

RI: Resistive index; AUC: Area under curve; SE: Standard error; RIdp: Dorsalis pedis artery resistive index; RItp: Tibialis posterior artery resistive index; RIpop: Popliteal artery resistive index. 
studies $^{[3]}$ and $\mathrm{CDU}^{[1,2,4,6]}$ studies examining the arterial diameter, direction of arterial flow, arterial flow pattern and velocity, and lumen filling have demonstrated a relationship between vascular deficiency and treatment resistance. In the present CDU study, we investigated the relationship between clubfoot deformity and the RI and PSV of major arteries of the foot. To the best of our knowledge, there have been no prior studies of the RI and PSV in clubfoot deformity. As vascular pathology has been suggested to contribute to clubfoot deformity, we investigated whether foot microcirculation is altered in affected patients. We analyzed CDU examinations of 27 patients with clubfoot deformity and 11 babies in the control group.

Most of the patients particularly in the surgical group were referred from other centers, therefore, we did not have their former data. We also did not have many of the former data for the conservative group. We could not use the existing classification systems and calculate the former scores of the patients for each group. Thus we designated the conservative group as treatment-sensitive and the surgical group as treatment-resistant.

We initially compared the PSV and RI values of the three major arteries of the foot in the four groups. The RIdp did not significantly differ among the four groups, whereas other variables showed significant differences (Table I). We then performed subgroup analysis, excluding RIdp (Table II); we found no statistically significant differences among the conservative, surgical, and healthy groups. There are two important aspects of this finding. First, the results did not show that RI and PSV change in accordance with the severity of clubfoot, or that they may be used as prognostic criteria as we mentioned in our hypothesis. This may be the result of the small number of patients in our cohort, as well as the heterogeneity of the cohort particularly with respect to the surgical group (i.e., neglected and resistant patients). A robust prospective study with a larger, homogenous cohort may demonstrate significant differences in the measured parameters. Table II shows that the PSV values of the healthy and control groups only exhibited significant differences in the PSVtp. In contrast, the RI showed significant differences in both the conservative versus control and the surgical versus control group comparisons. Thus, vascular pathologies are present in both the deformed side in unilateral cases and in the contralateral healthy foot. Accordingly, we presume that in clubfoot deformity, vascular deficiency is a component of clubfoot, the RI and PSV of the arteries together determine the phenotype of clubfoot: increased arterial flow may prevent the onset of deformity.

Vascular changes may occur throughout the body, such that vascular compliance and vascular resistance are affected. These aspects should be investigated in a future study. In some studies of unilateral clubfoot deformity, the healthy side in patients with deformity is considered normal and is therefore used as the control group. ${ }^{[3,5,14]}$ We propose that the healthy foot in such patients should not be used as the control group. There are two primary hypotheses regarding vascular deficiency in clubfoot deformity. In one hypothesis, vascular deficiency is the main pathology and causes clubfoot deformity. ${ }^{[15,16]}$ In the other hypothesis, vascular deficiency is regarded as a consequence of the foot deformity; after treatment of the foot deformity, the arterial pattern improves. ${ }^{[2]}$ Our results support the first hypothesis, as there were no statistically significant differences in the RI and PSV values among the conservative, surgical, and healthy groups. We cannot fully reject the second hypothesis, as the evolution of vascular structures may be multifactorial. A prospective study may enable the analysis of modifiable and fixed factors that affect vascular structures.

Because the results of the conservative, surgical, and healthy groups differed from those of the control group, we performed ROC curve analysis to determine the optimal cut-off values. A cut-off point for the AUC of $>0.8$ was regarded as very good; a cut-off point of $>0.9$ was regarded as perfect. ${ }^{[17]}$

For AUC analysis of PSV, we initially compared each group with the control group. The highest AUC values were observed in the tp artery group (Table III). Following subgroup analysis, we compared all groups together with the control group. The PSVtp AUC value was the highest of the three arteries, at $0.918 \pm 0.03$ ( $\mathrm{p}=0.001$ ); this was $>0.9$, indicating a perfect cut-off point at $54 \mathrm{~cm} /$ second. Thus, the PSV of the tp artery in patients with clubfoot is presumed to be $<54 \mathrm{~cm} /$ second for most deformed feet (Table III).

For AUC analysis of RI, we first compared each group with the control group. The highest AUC values were observed in the pop artery group (Table IV). We compared all groups together with the control group and analyzed the AUC values for RI. The RIpop AUC value was the highest of the three arteries, at $0.938 \pm 0.06(\mathrm{p}=0.001)$ and was $>0.9$, indicating a perfect cut-off point of 0.77 . Thus, RI values $>0.77$ are likely to be related to clubfoot deformity (Table IV).

These results support the first part of our hypothesis that the RI and PSV values of major foot 
arteries are important parameters that influence the onset of clubfoot. Peak systolic velocity tp and RIpop are particularly useful parameters, for which AUC analysis indicated perfect cut-off points. RI values depend on the pathology, specific organ analyzed, and the age of the patient. Renal RI can show renal microcirculation and is particularly useful in the assessment of patients who have undergone renal transplantation; ${ }^{[18]}$ splenic RI and renal RI are used as predictors of hemorrhagic shock development within the first 24 hours postoperatively. ${ }^{[19]}$ Renal $\mathrm{RI}$ is considered to be normal at $<0.7$, indeterminate between $0.7-0.8$, and elevated at $>0.8 .^{[20]}$ Importantly, there are no such reference values for clubfoot in babies. To the best of our knowledge, this is the first study regarding this issue.

We had some limitations in this study. Our study is not a blinded study and we did not have the first examination reports and the scores of any classification system. Hence, we accepted deformities as sensitive or resistive according to the type of treatment. The other issue is that the number of surgeries seems to be very high. In our district, the socioeconomic status of the people is low and there is a huge Syrian refugee population. Many clubfoot patients may not be treated till to very late ages or the parents may not adhere to the treatment process, causing the deformities to recur. We applied manipulation and casting to all of these neglected patients and successfully treated most of them conservatively. However, some of these patients were treated surgically because of their advanced deformities. To overcome these limitations, well-designed prospective blinded studies should be conducted from the beginning of the treatment.

In conclusion, we think that vascular deficiency is a component of clubfoot deformity. Resistive index and PSV provide information regarding microcirculation in feet, and may be used as important parameters for clubfoot patients. In clubfoot, lower extremity arterial structures are affected bilaterally, although the deformity may be unilateral. Although we could not establish these parameters as prognostic criteria for clubfoot in the present study, a well-designed prospective study with more patients may reveal further valuable information regarding these parameters.

\section{Declaration of conflicting interests}

The authors declared no conflicts of interest with respect to the authorship and/or publication of this article.

\section{Funding}

The authors received no financial support for the research and/or authorship of this article.

\section{REFERENCES}

1. Shaheen S, Bahar MEH, Mohammed AHA, Elbadri SFA, Johari A. Arterial tree anomalies in patients with clubfoot: an investigation carried out at Soba University Hospital. J Pediatr Orthop B 2018;27:67-72.

2. Pinto JA, Blumetti FC, Iha LAN, Terasaka MK, Sodré H, Ishida A. Evalu-ation of arterial anatomy in clubfoot with color doppler ultrasonography. Acta Ortop Bras 2008;16:270-4.

3. Merrill LJ, Gurnett CA, Siegel M, Sonavane S, Dobbs MB. Vascular abnormalities correlate with decreased soft tissue volumes in idiopathic clubfoot. Clin Orthop Relat Res 2011;469:1442-9.

4. Katz DA, Albanese EL, Levinsohn EM, Hootnick DR, Packard DS Jr, Grant WD, et al. Pulsed color-flow Doppler analysis of arterial deficiency in idiopathic clubfoot. J Pediatr Orthop 2003;23:84-7.

5. Yildirim T, Bursali A, Tonbul M, Sakizlioglu SS, Camurcu Y. Does the Ponseti technique affect the vascular development in patients with congenital talipes equinovarus? J Pediatr Orthop B 2015;24:6-10.

6. Munajat I, Yoysefi M, Nik Mahdi NM. Deficient dorsalis pedis flow in severe idiopathic clubfeet: Does Ponseti casting affect the outcome? Foot 2017;32:30-4.

7. Kruse L, Gurnett CA, Hootnick D, Dobbs MB. Magnetic resonance angiography in clubfoot and vertical talus: a feasibility study. Clin Orthop Relat Res 2009;467:1250-5.

8. Sodre H, Bruschini S, Mestriner LA, Miranda F Jr, Levinsohn EM, Packard DS Jr, et al. Arterial abnormalities in talipes equinovarus as assessed by angiography and the Doppler technique. J Pediatr Orthop 1990;10:101-4.

9. Edelson JG, Husseini N. The pulseless club foot. J Bone Joint Surg [Br] 1984;66:700-2.

10. Pourcelot L. Velocimetrie ultrasonore Doppler. Paris: Editions INSERM; 1974. p. 213-40.

11. Stefan G, Capusa C, Stancu S, Petrescu L, Nedelcu ED, Andreiana I, et al. Abdominal aortic calcification and renal resistive index in patients with chronic kidney disease: is there a connection? J Nephrol 2014;27:173-9.

12. Tublin ME, Bude RO, Platt JF. The resistive index in renal Doppler sonography: where do we stand? AJR Am J Roentgenol 2003;180:885-92.

13. Atik OŞ. Is there something new and interesting in my article? Eklem Hastalik Cerrahisi 2019;30:69.

14. Ippolito E, De Maio F, Mancini F, Bellini D, Orefice A. Leg muscle atrophy in idiopathic congenital clubfoot: is it primitive or acquired? J Child Orthop 2009;3:171-8.

15. Hootnick DR, Levinsohn EM, Crider RJ, Packard DS Jr. Congenital arterial malformations associated with clubfoot. A report of two cases. Clin Orthop Relat Res 1982;167:160-3.

16. Miedzybrodzka Z. Congenital talipes equinovarus (clubfoot): a disorder of the foot but not the hand. J Anat 2003;202:37-42.

17. Šimundić AM. Measures of Diagnostic Accuracy: Basic Definitions. EJIFCC 2009;19:203-11.

18. Naesens M, Heylen L, Lerut E, Claes K, De Wever L, Claus F, et al. Intrarenal resistive index after renal transplantation. $\mathrm{N}$ Engl J Med 2013;369:1797-806.

19. Corradi F, Brusasco C, Garlaschi A, Santori G, Vezzani A, Moscatelli $\mathrm{P}$, et al. Splenic Doppler resistive index for early detection of occult hemorrhagic shock after polytrauma in adult patients. Shock 2012;38:466-73.

20. Cano H, Castenada DA, Patino N, Perez HC, Sanchez M, Lozano E, et al. Resistance index measured by Doppler ultrasound as a predictor of graft function after kidney transplantation. Transplant Proc 2014;46:2972-4. 